\title{
Precise Hole Drilling in PMMA Using 1064 nm Diode Laser CNC Machine
}

\author{
Jinan A. Abdulnabi, ${ }^{1}$ Thaier A. Tawfiq, ${ }^{1}$ Anwaar A. Al-Dergazly, ${ }^{2}$ Ziad A. Taha, ${ }^{1}$ and Khalil I. \\ Hajim $^{1}$
}

${ }^{1}$ Institute of Laser for Postgraduste Studies, University of Baghdad, P.O. Box 47314, Jadriha, Baghdad, Iraq

${ }^{2}$ Laser and Optoelctronics Engineering Department, Al-Nahrain university, Jadriha, Baghdad, Iraq

Correspondence should be addressed to Ziad A. Taha, zddiesel@yahoo.com

Received 30 December 2010; Accepted 21 February 2011

Academic Editor: J. Dutta Majumdar

Copyright ( 2011 Jinan A. Abdulnabi et al. This is an open access article distributed under the Creative Commons Attribution License, which permits unrestricted use, distribution, and reproduction in any medium, provided the original work is properly cited.

This paper represents the outcome of efforts that intended to achieve laser hole drilling execution in polymethylmethacrylate (PMMA) of $2.5 \mathrm{~mm}$ thickness using $1064 \mathrm{~nm}$ diode laser of $5 \mathrm{~W}$ output power. Different laser beam powers, exposure time, and positions of the laser spot were taken into consideration with respect to the workpiece. The workpieces were tested in the existence of low-pressure assist gas (20-60 mmHg of air). The experimental results were supported by the predicted results of the analytical model.

\section{Introduction}

The conduction of heat in a three-dimensional solid is given by the solution of the following equation:

$$
\begin{aligned}
\rho C_{P} \frac{\partial T}{\partial t}= & \frac{\partial}{\partial x}\left(K \frac{\partial T}{\partial x}\right)+\frac{\partial}{\partial y}\left(K \frac{\partial T}{\partial y}\right) \\
& +\frac{\partial}{\partial z}\left(K \frac{\partial T}{\partial z}\right)+A(x, y, z, t),
\end{aligned}
$$

where, the thermal conductivity $K\left(\mathrm{Wcm}^{-1} \mathrm{~K}^{-1}\right)$, the density $\rho\left(\mathrm{g} \mathrm{cm}^{-3}\right)$, and the specific heat $C_{P}\left(\mathrm{Jkg}^{-1} \mathrm{~K}^{-1}\right)$ are dependent on the temperature and position. The rate of the applied heat to the solid is $A(x, y, z, t)$ per unit time per unit volume, and $t$ is the time [1].

Using the cylindrical coordinates $r$ and $z$ (Figure 1), the temperature distribution is $[1,2]$

$$
\begin{aligned}
& T(r, z, t) \\
& =\frac{P \varepsilon}{2 \pi \mathrm{a} K} \int_{0}^{\infty} J_{0}(m r) J_{1}(m a) \\
& \times\left\{\exp (-m z) \operatorname{erfc}\left[\frac{z}{2(k t)^{1 / 2}}-m\left(-(k t)^{1 / 2}\right)\right]\right. \\
& \left.-e(m z) \operatorname{erfc}\left[\frac{z}{2(k t)^{1 / 2}}+m(k t)^{1 / 2}\right]\right\} \frac{d m}{m} \\
& +T_{0} \text {, }
\end{aligned}
$$

where, $r$ is the radial coordinate (hole radius), $z$ is the axial coordinate (thermal penetration depth), $J_{o}$ and $J_{1}$ are Bessel functions of the first kind, $P$ is the constant power during a laser pulse, $a$ is the radius of the laser spot at the surface, $K$ is the thermal conductivity of the material, $k$ is the thermal diffusivity, $\varepsilon$ is the fraction of incident radiation absorbed, $m$ is an integer that represents the limit of integration, $t$ is the exposure time, and $T_{o}$ is the initial temperature.

The numerical solution of (2) for determining the temperature distribution as a function of time at any point 


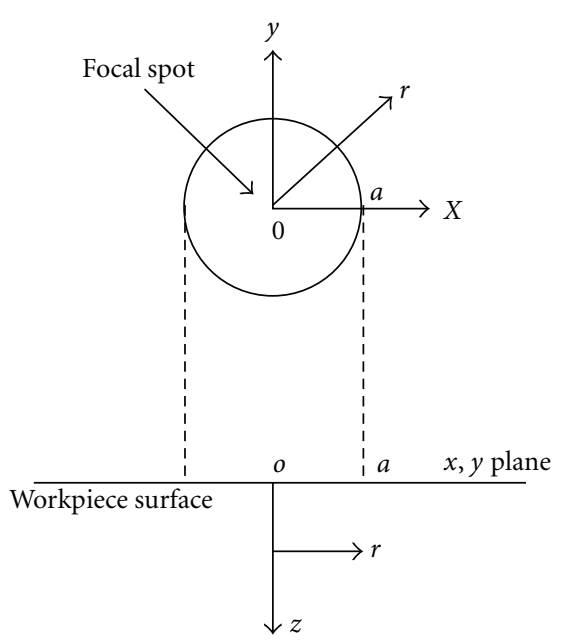

Figure 1: Coordinate system [1].

inside the material along the $Z$-axis for $r=0$ is given by $[1,2]$

$$
\begin{aligned}
& T(0, z, t) \\
& =\frac{2 P \varepsilon(k t)^{1 / 2}}{\pi a^{2} K}\left\{i \operatorname{erfc}\left[\frac{z}{2(k t)^{1 / 2}}\right]-i \operatorname{erfc}\left[\frac{\left(z^{2}+a^{2}\right)^{1 / 2}}{2(k t)^{1 / 2}}\right]\right\} \\
& \quad+T_{0} .
\end{aligned}
$$

The dimensionless variables for temperature and time, respectively are defined as $[1,2]$

$$
\begin{gathered}
\theta=\frac{T a K \pi}{P \varepsilon}, \\
\Gamma=\frac{2(k t)^{1 / 2}}{a} .
\end{gathered}
$$

Hence, (3) becomes

$$
\theta(0, z, \tau)=\Gamma\left[i \operatorname{erfc} \frac{z}{a \Gamma}-i \operatorname{erfc} \frac{\left(z^{2}+a^{2}\right)^{1 / 2}}{a \Gamma}\right]+T_{0}
$$

For steady-state condition at any depth below or at the center of the focal spot, $t \rightarrow \infty$ in $(6)[1,2]$

$$
\begin{gathered}
T(0,0, t)=\frac{2 P \varepsilon(k t)^{1 / 2}}{\pi a^{2} K}\left\{\frac{1}{\pi^{1 / 2}}-i \operatorname{erfc}\left[\frac{a}{2(K t)^{1 / 2}}\right]\right\}+T_{0} \\
\theta(0, z, \infty)=\frac{1}{a}\left[\left(z^{2}+a^{2}\right)^{1 / 2}-z\right] .
\end{gathered}
$$

This implies that the maximum surface temperature attainable is given by [1]

$$
T(0,0, \infty)=\frac{P \varepsilon}{\pi a K} .
$$

Figure 2 illustrates a plot diagram for (6) as the variation of the dimensionless temperature $\theta$ with $\tau=\Gamma^{2}=4 k t / a^{2}$ and

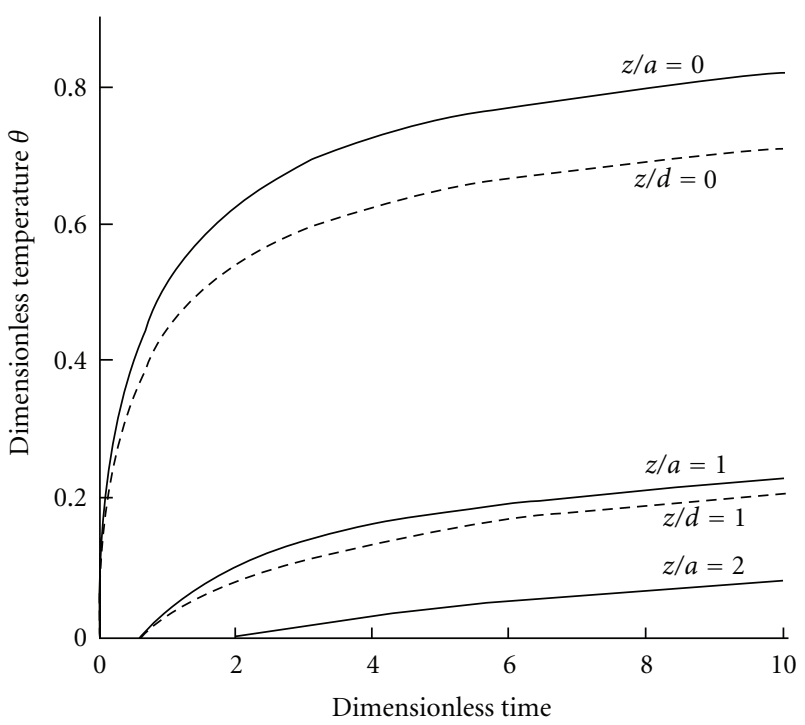

Figure 2: Dimensionless temperature $\theta$ versus dimensionless time for various depths when heating with continuous disk (-) and Gaussian (- -) sources [1].

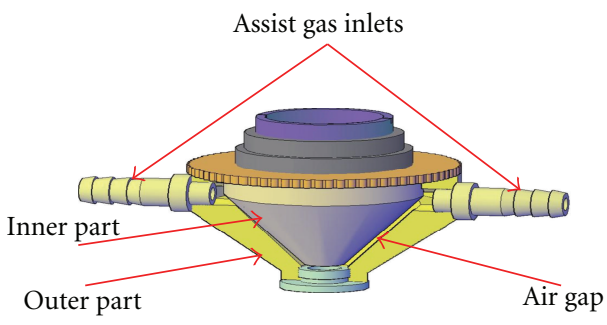

FIgUre 3: The designed nozzle.

depth below the focal spot. The temperature rises rapidly at first and approaches $75 \%$ of its steady-state value within $\tau=4$ or $t=a^{2} / k$, then the change in temperature with time proceeds at a progressively decreasing rate. The time $t=a^{2} / K$ can, therefore, be considered as the thermal time constant [1].

\section{Experimental Work}

A special nozzle for the laser head was designed and constructed for achieving the optimum performance as shown in Figure 3.

In the absence of the assist gas nozzle, the output power of the laser head was $2.75 \mathrm{~W}$ as examined by a power meter type (Gentec TPM $300 \mathrm{CE}$ ) as an average value of the output power. In this work, the nozzle was designed in a way that acts as a normal assist gas nozzle and as an assist gas nozzle with variable orifice diameters (with a changeable nozzle tips of $0.4,0.6,0.8,1,1.2,1.5$, and $3.0 \mathrm{~mm}$ in diameters), as shown in Figure 4, that were used as an a apertures (placed at the waist of the collimating lens $[3,4])$ to allow choosing various values of the laser beam output power and suppress the higher-order modes. 


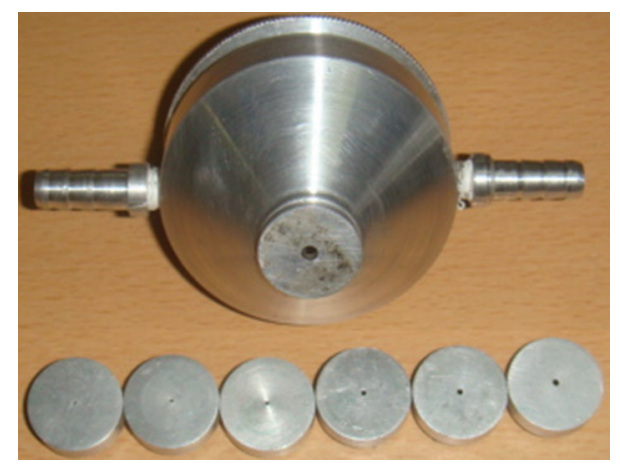

FIgURE 4: The assist gas nozzle and the seven different tips.

TABLE 1: The theoretical values of the aspect and taper ratios at different powers.

\begin{tabular}{lcccc}
\hline \multirow{2}{*}{ Power (W) } & \multicolumn{2}{c}{ Hole Diameter mm } & \multirow{2}{*}{ Aspect Ratio $A_{r}$} & Taper Ratio $T_{r}$ \\
& Inlet & Outlet & & \\
\hline 2.45 & 0.700 & 0.300 & 3.571 & 0.428 \\
1.82 & 0.650 & 0.200 & 3.846 & 0.308 \\
0.96 & 0.500 & 0.200 & 5.0 & 0.400 \\
\hline
\end{tabular}

All the workpieces were illuminated by the laser beam for many different time periods in order to reach the vaporization temperature and executing drilling process. The drilling process was examined for different laser spot positions (at the surface, at the mid surface, and at the lower surface), without the use of assist gas, and with the assist gas (the used pressures were 20,30, 40,50, and $60 \mathrm{mmHg}$ ).

Figure 5 shows the values of the aspect ratio (depth to diameter) and the taper ratio (outlet to inlet diameter) using laser power of $2.45 \mathrm{~W}$, the focal position at the surface of the workpiece, and the assist gas pressure of $20 \mathrm{mmHg}$ for 11 exposures time.

Figures 8, 9, and 10 illustrate the temperature distributions for different working conditions.

\section{Simulation Results}

The maximum temperature in the center of the focus at the surface was measured from (7). This temperature was substitute in (2) for each used output laser power with the rest values mentioned in this equation $(a, K, k, t, \ldots$, etc. $)$ and plotting the temperature distribution. The value of $t$ that substituted in (2) was measured as the thermal time constant $\left(t=a^{2} / k\right)$ for $z$ below the focal spot. This $t$ represents the maximum exposure time needed for the material to reach the vaporization temperature over which the heat diffused inside the material and not along the depth. This value of $t$ was used for the rest stages of the drilling process. The hole depth was measured using the plot diagram and substituted in (8) for determining $\theta$. This $\theta$ was substituted in (4) for determining the maximum temperature at this depth, which will be considered as the new surface. The newly measured

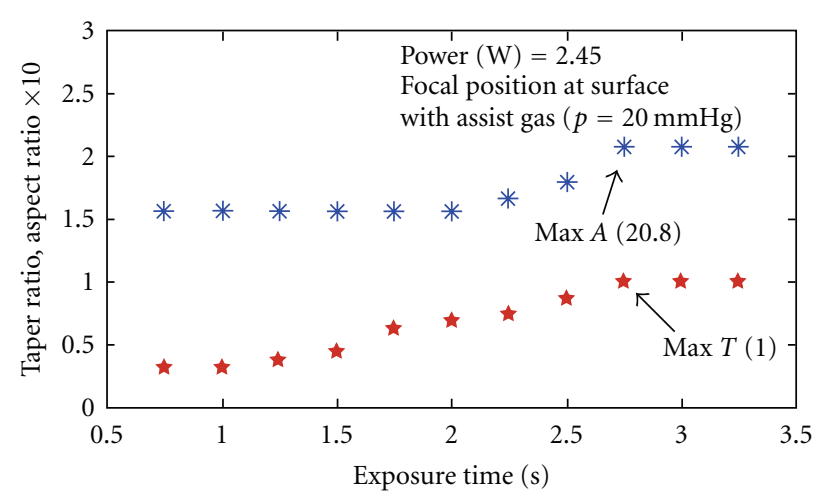

* $A$ versus $t$

$\star T$ versus $t$

Figure 5: Different holes drilled by $P=2.45 \mathrm{~W}$, focal position at the surface, and with $20 \mathrm{mmHg}$ of assist gas.

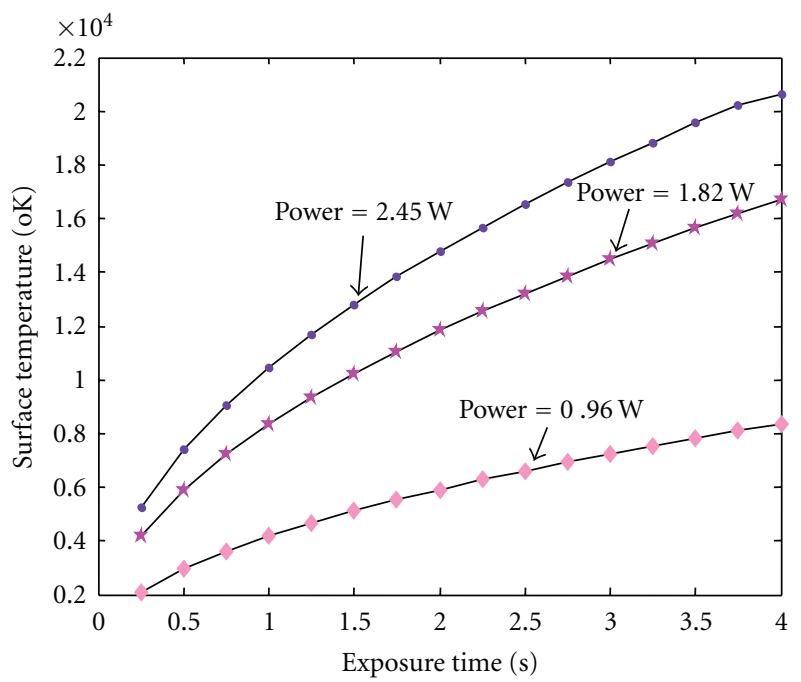

Figure 6: The laser beam exposure time versus the surface temperature.

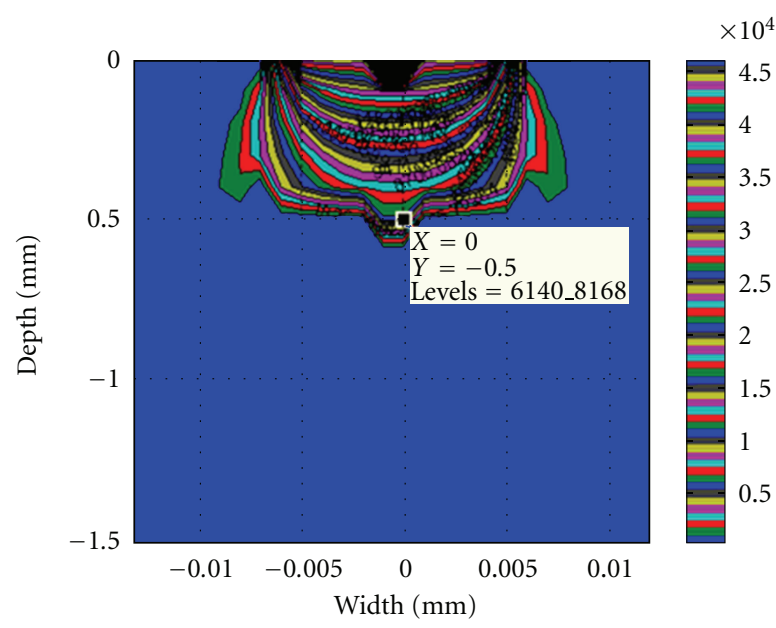

FIGURE 7: The hole depth versus the hole radius. 
TABLE 2: The different experimental values of $A_{r}$ and $T_{r}$ at different working conditions.

\begin{tabular}{|c|c|c|c|c|c|c|}
\hline Power $(\mathrm{W})$ & Focal position & Taper ratio & Taper exposure time (s) & Aspect ratio & Aspect exposure time (s) & Assist gas pressure $(\mathrm{mmHg})$ \\
\hline 2.45 & At surface & 1 & 2.75 & 20.8 & 2.75 & 20 \\
\hline$=$ & $=$ & 1 & 2.5 & 16.6 & 2.5 & 30 \\
\hline$=$ & $=$ & 1 & 2.5 & 20.8 & 1.75 & 40 \\
\hline$=$ & $=$ & 0.9 & 3 & 22.2 & 0.75 & 50 \\
\hline$=$ & $=$ & 0.9 & 0.75 & 22.7 & 0.75 & 60 \\
\hline$=$ & At mid surface & 1 & 1.75 & 16.6 & 1.5 & 20 \\
\hline$=$ & $=$ & 0.8 & 1.75 & 3.7 & 1.25 & 30 \\
\hline$=$ & $=$ & 1 & 1.25 & 17.8 & 1.25 & 40 \\
\hline$=$ & $=$ & 0.9 & 3.5 & 4 & 3.5 & 50 \\
\hline$=$ & $=$ & 0.9 & 3.75 & 7.8 & 3.5 & 60 \\
\hline$=$ & At lower surface & 0.43 & 1.75 & 4.3 & 1.75 & 20 \\
\hline$=$ & $=$ & 0.54 & 3.75 & 4.5 & 3.75 & 30 \\
\hline$=$ & $=$ & 0.6 & 4 & 4.5 & 3.75 & 40 \\
\hline$=$ & $=$ & 0.37 & 1.5 & 4.5 & 4 & 50 \\
\hline$=$ & $=$ & 0.4 & 4 & 4.4 & 0.75 & 60 \\
\hline$=$ & $=$ & 1 & 0.75 & 31 & 0.75 & 70 \\
\hline 2.45 & At surface & 0.48 & 3.75 & 3.3 & 2 & Non \\
\hline$=$ & At mid surface & 0.5 & 3.5 & 4 & 2 & $=$ \\
\hline$=$ & At lower surface & 0.6 & 3.75 & 3.5 & 2 & $=$ \\
\hline 1.82 & At surface & 0.5 & 3.75 & 3.5 & 2.5 & $=$ \\
\hline 0.96 & At surface & 0.56 & 3.25 & 5 & 2.5 & $=$ \\
\hline
\end{tabular}

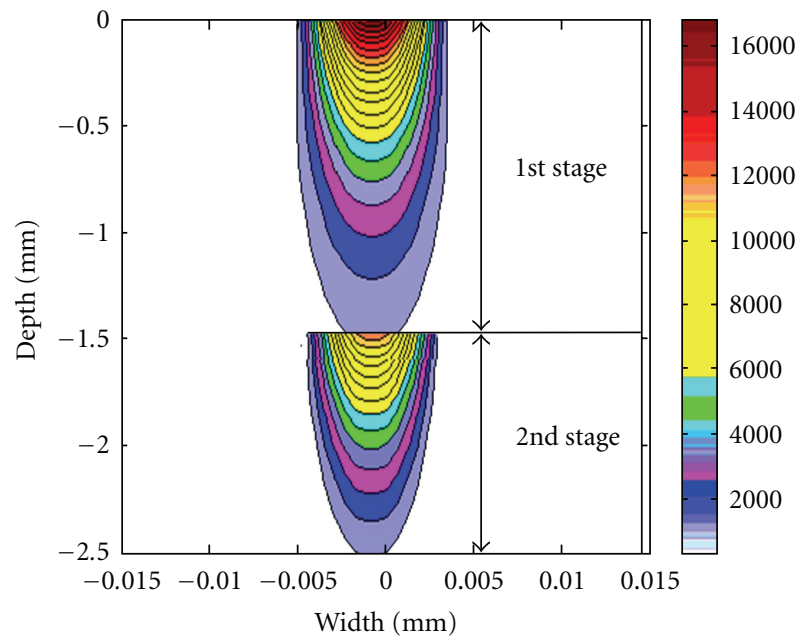

Figure 8: The first-stage temperature distribution; exposure time $(s)=2.25$, total power $(W)=2.45$, and surface temperature $=$ $1.5364 \mathrm{e}+004$. The second-stage temperature distribution; exposure time $(\mathrm{s})=2.25$, total power $(W)=0.3528$, and surface temperature $=2.2124 \mathrm{e}+003$.

temperature was substituted in (9) for measuring the new laser power at this depth. The above-mentioned steps were followed again many times until the hole covered the whole thickness of the workpiece. Knowing that each time the new thickness was added to the depth of the previous stage and then substituted in (2).

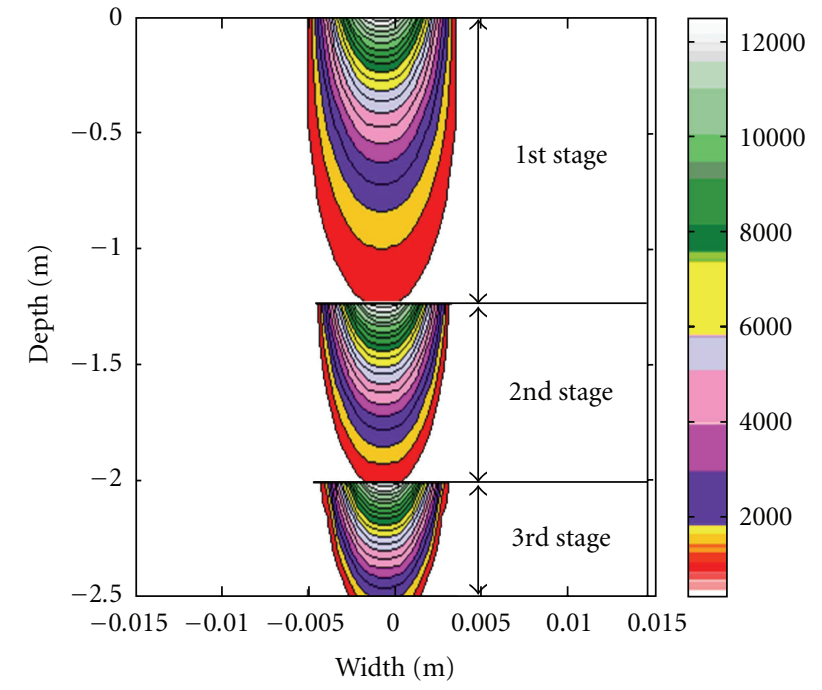

FIgURE 9: The first-stage temperature distribution; exposure time $(\mathrm{s})=2.25$, total power $(W)=1.82$, and surface temperature $=$ $1.1413 \mathrm{e}+004$. The second-stage temperature distribution; exposure time $(s)=2.25$, total power $(W)=0.2953$, and surface temperature $=1.8518 \mathrm{e}+003$. The third-stage temperature distribution; exposure time $(s)=2.25$, Total power $(W)=0.19$, and surface temperature $=1.2559 \mathrm{e}+003$.

\section{Results and Discussion}

The analytical steps were followed for laser output powers $2.45 \mathrm{~W}, 1.82 \mathrm{~W}$, and $0.96 \mathrm{~W}$ using the nozzle orifices of $3 \mathrm{~mm}, 1.5 \mathrm{~mm}$, and $1.2 \mathrm{~mm}$, the spot radius measured as 


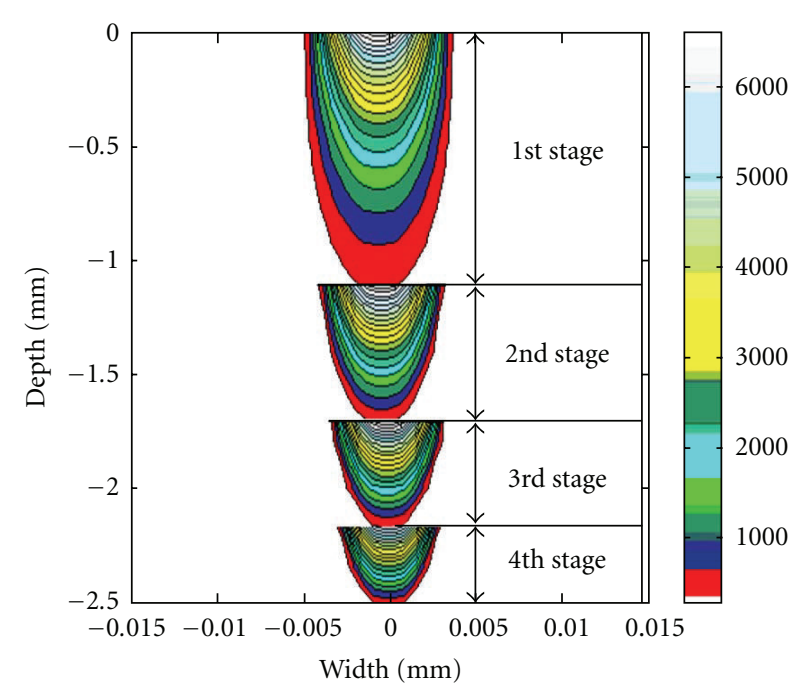

Figure 10: The first-stage temperature distribution; exposure time $(s)=2.25$, total power $(W)=0.96$, and surface temperature $=$ $6.0201 \mathrm{e}+003$. The second-stage temperature distribution; exposure time $(s)=2.25$, total power $(W)=0.1782$, and surface temperature $=1.1175 \mathrm{e}+003$. The third-stage temperature distribution; exposure time $(s)=2.25$, total power $(W)=0.19$, and surface temperature $=1.2559 \mathrm{e}+003$. The forth-stage temperature distribution; exposure time $(s)=2.25$, total power $(W)=0.0989$, and surface temperature $=620.196$.

$0.5 \mathrm{~mm}$, The thermal time constant $t$ was $2.25 \mathrm{~s}, K$ of the workpiece material (PMMA) $0.2 \times 10^{-3} \mathrm{~W} \mathrm{~mm}^{-1}{ }^{\circ} \mathrm{K}^{-1}, k$ of the workpiece material is $0.11 \mathrm{~mm}^{2} \mathrm{~s}^{-1}$, and the reflectivity $R$ of the workpiece material was assumed as 0.01 . Therefore, the emissivity of the surface of the workpiece $\varepsilon=1-R=0.99$, and the exposure time versus the surface temperature was plotted for each of the used powers, $2.45 \mathrm{~W}, 1.82 \mathrm{~W}$, and $0.96 \mathrm{~W}$ as shown in Figure 6.

A MATLAB package was used for presenting the case under study. For one stage drilling process, it was found that whatever the increase in the exposure time the hole did not exceed certain depth of the whole thickness of the workpiece and the heat was diffused (dissipated) inside the material and not along the depth (Figure 7).

The aspect ratio (ratio of depth to diameter) and the taper ratio (ratio of outlet to inlet diameter) of the drilled holes by using laser beam powers; $2.45 \mathrm{~W}, 1.82 \mathrm{~W}$, and $0.96 \mathrm{~W}$ as measured from Figures 8, 9, and 10 are listed in Table 1.

These values of $A_{r}$ and $T_{r}$ clarify that irradiating PMMA workpiece of $2.5 \mathrm{~mm}$ thickness by $1064 \mathrm{~nm} \mathrm{CW}$ diode laser of $1 \mathrm{~W}$ output power and exposure time of $2.25 \mathrm{~s}$ leads to achieving an acceptable quality of the hole drilling process that matches the most improved values represented by the highest aspect ratio $(20-30)$ and lowest taper ratio $(\approx 1)$ $[5,6]$.

\section{Conclusion}

The experimental results for different working conditions that were illustrated in Table 2 show that without the use of the assist gas the best holes can be achieved by focusing almost of $1 \mathrm{~W}$ laser output power on the surface of the chosen workpiece material for about $2.5 \mathrm{~s}$ which matches with the best result of the analytical model as shown in the last row of the table.

Moreover, the use of the low-pressure assist gas of about $60 \mathrm{mmHg}$ with laser output power of $2.45 \mathrm{~W}$ and focusing the spot on the surface of the workpiece enhanced the drilling process and reduced the required exposure time. Therefore, this study concluded that for executing laser hole drilling process in black acrylic (PMMA) material of $2.5 \mathrm{~mm}$ thickness using CW diode laser of low laser output power around $1 \mathrm{~W}$ with the absence of the assist gas, the focal position represents the most affecting parameter for getting best results (highest aspect ratio and lowest taper ratio) while when using higher laser output power of $2.45 \mathrm{~W}$ with the existence of the assist gas, the most affecting parameters are the assist gas pressure and focal position.

\section{References}

[1] W. W. Duley, $\mathrm{CO}_{2}$ Laser Effects and Applications, Academic Press, New York, NY, USA, 1976.

[2] H. S. Carslaw and J. C. Jaegar, Conduction of Heat in Solids, Oxford Press, Oxford, UK, 1969.

[3] R. Menzel, Photonics, Linear and Nonlinear Interaction of Light and Matter, Springer, Berlin, Germany, 2001.

[4] J. F. Ready, LIA Handbook of Laser Materials Processing, Laser Institute of America, Magnolia Publishing, Orlando, Fla, USA, 2001.

[5] H. El-Hofy, Advanced Machining Processes, Nontraditional and Hybrid Machining Processes, Production Engineering Department, Alexandria University, Alexandria, Egypt, 2005.

[6] W. M. Steen, Laser Material Processing, Springer, London, UK, 2nd edition, 1998. 

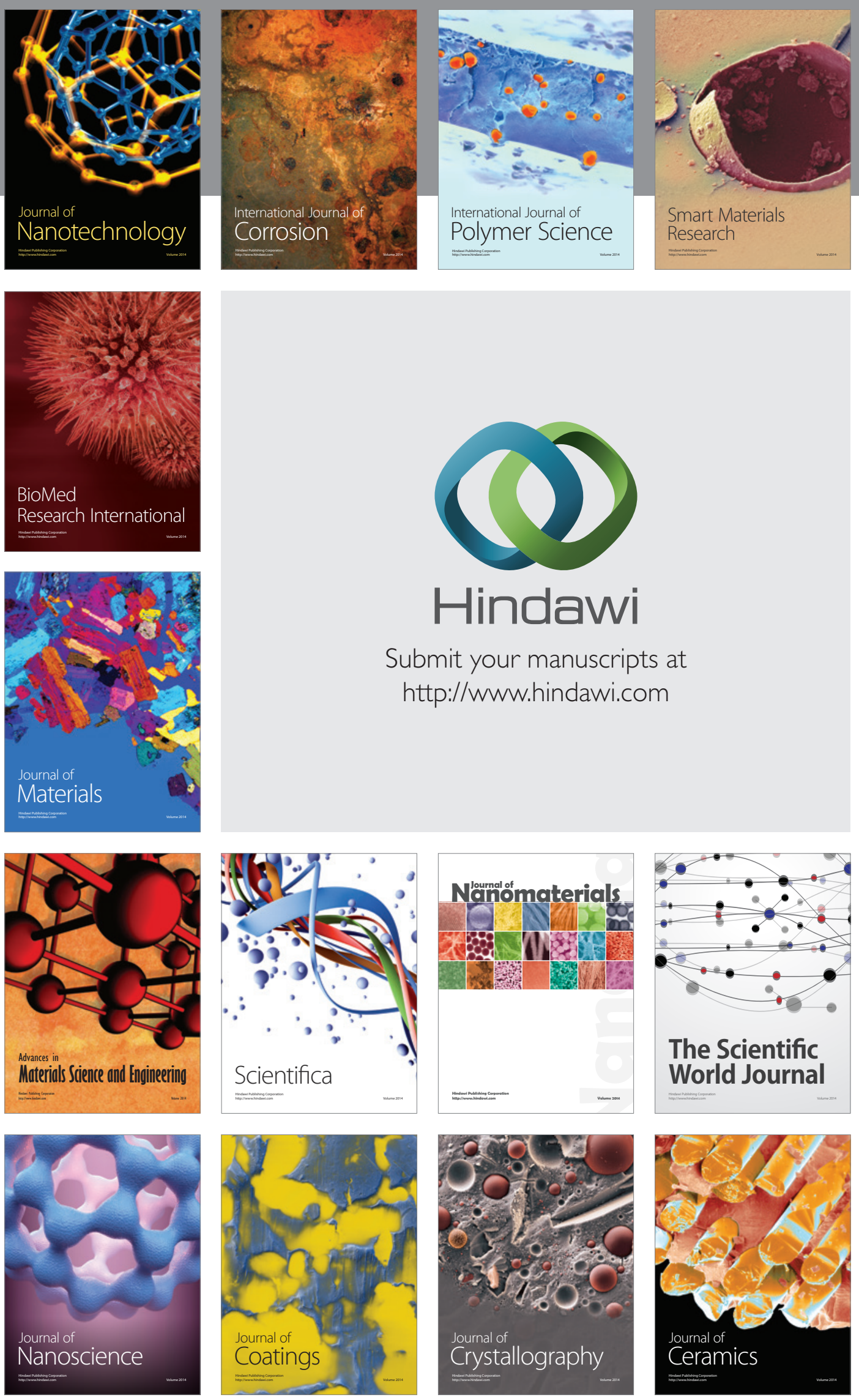

The Scientific World Journal

Submit your manuscripts at

http://www.hindawi.com

\section{World Journal}

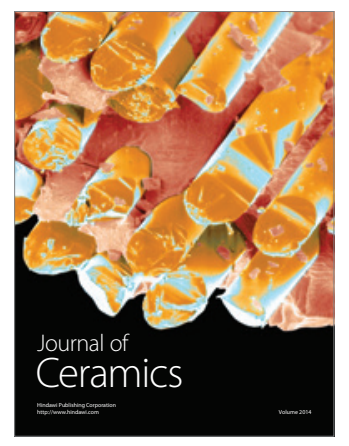

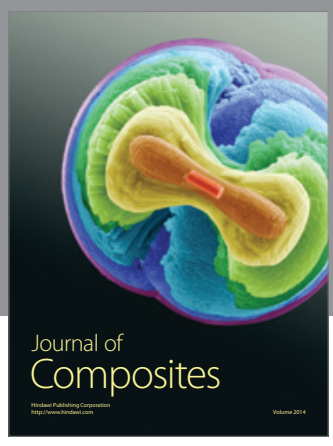
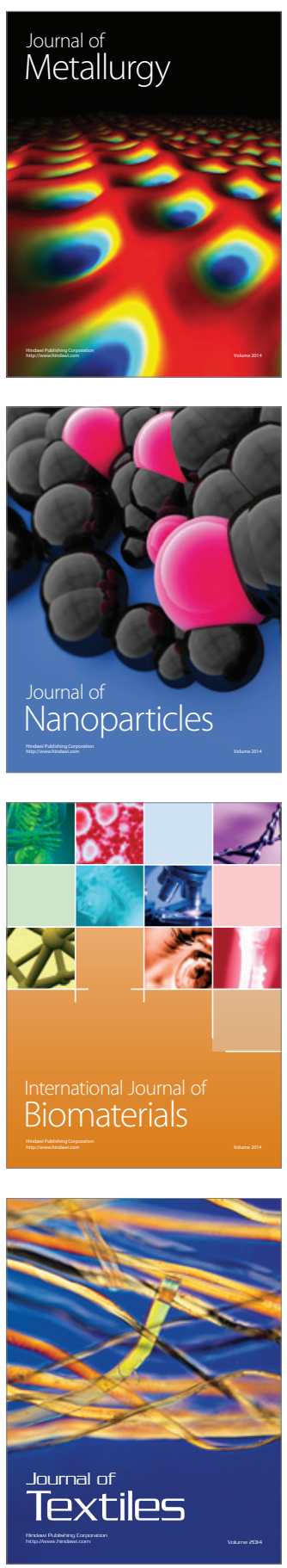